\title{
Vascular and haemodynamic issues of brain ageing
}

\author{
Lucy Beishon $^{1}$ (D) Rebecca H. Clough ${ }^{1}$ - Meeriam Kadicheeni ${ }^{1} \cdot$ Tamara Chithiramohan $^{1} \cdot$ Ronney B. Panerai ${ }^{1,2}$. \\ Victoria J. Haunton ${ }^{1,2} \cdot$ Jatinder S. Minhas ${ }^{1,2} \cdot$ Thompson G. Robinson ${ }^{1,2}$
}

Received: 1 September 2020 /Revised: 14 December 2020 / Accepted: 16 December 2020 / Published online: 13 January 2021

(C) The Author(s) 2021

\begin{abstract}
The population is ageing worldwide, thus increasing the burden of common age-related disorders to the individual, society and economy. Cerebrovascular diseases (stroke, dementia) contribute a significant proportion of this burden and are associated with high morbidity and mortality. Thus, understanding and promoting healthy vascular brain ageing are becoming an increasing priority for healthcare systems. In this review, we consider the effects of normal ageing on two major physiological processes responsible for vascular brain function: Cerebral autoregulation (CA) and neurovascular coupling (NVC). CA is the process by which the brain regulates cerebral blood flow $(\mathrm{CBF})$ and protects against falls and surges in cerebral perfusion pressure, which risk hypoxic brain injury and pressure damage, respectively. In contrast, NVC is the process by which CBF is matched to cerebral metabolic activity, ensuring adequate local oxygenation and nutrient delivery for increased neuronal activity. Healthy ageing is associated with a number of key physiological adaptations in these processes to mitigate age-related functional and structural declines. Through multiple different paradigms assessing CA in healthy younger and older humans, generating conflicting findings, carbon dioxide studies in CA have provided the greatest understanding of intrinsic vascular anatomical factors that may mediate healthy ageing responses. In NVC, studies have found mixed results, with reduced, equivalent and increased activation of vascular responses to cognitive stimulation. In summary, vascular and haemodynamic changes occur in response to ageing and are important in distinguishing "normal" ageing from disease states and may help to develop effective therapeutic strategies to promote healthy brain ageing.
\end{abstract}

Keywords Dynamic cerebral autoregulation $\cdot$ Neurovascular coupling $\cdot$ Transcranial Doppler ultrasonography $\cdot$ Ageing

\section{Introduction}

The population is ageing, and by 2050 , one in six people will be aged over 65 worldwide [75]. Cerebrovascular disease is a prominent cause of morbidity and mortality, and the prevalence of the cerebrovascular disease is increasing with the

Jatinder S. Minhas and Thompson G. Robinson are joint senior authors.

This article is part of the special issue on Aging Brain in Pflügers Archiv_European Journal of Physiology

Lucy Beishon

1b330@1e.ac.uk

1 Department of Cardiovascular Sciences, University of Leicester, Robert Kilpatrick Clinical Sciences Building, Leicester LE2 7LX, UK

2 NIHR Leicester Biomedical Research Centre, British Heart Foundation Cardiovascular Research Centre, Glenfield Hospital, Leicester, UK ageing population [123]. Indeed, 15 million people worldwide are affected by stroke, $60 \%$ of whom are aged over 70 [123] and 46.8 million affected by dementia [98]. Many research studies have focussed on the vascular and haemodynamic changes involved in cerebrovascular disease. However, it is important to first understand the haemodynamic changes associated with normal ageing, in order to delineate these from pathological changes that may occur in disease states.

There are multiple techniques that can be employed to assess the vasculature and haemodynamics of the brain. Transcranial Doppler ultrasonography (TCD) allows for the assessment of cerebral haemodynamics in a non-invasive manner, by continuous monitoring of beat-to-beat cerebral blood flow (CBF) velocity as an approximation of CBF [85]. Near-infrared spectroscopy (NIRS) exploits the differences in infrared spectra absorption between oxygenated (oxyHb) and deoxygenated haemoglobin (dexoyHb) to measure relative changes in their concentration [23]. NIRS can therefore be used to measure tissue oxygenation and as an indirect measure of CBF [23]. Furthermore, functional 
magnetic resonance imaging (fMRI) and positron emission tomography (PET) can be used indirectly to measure neural activation [3].

An important factor of vascular ageing is arterial stiffness, which is known to increase with age and can be a predictor of end-organ damage [52]. Arterial stiffness is most commonly assessed using pulse wave velocity (PWV), directly at the level of the aorta, or between the carotid-femoral or brachialankle arterial sites [131]. Longitudinal epidemiological studies have shown arterial stiffness can progress at the average rate of 0.2 to $0.7 \mathrm{~m} / \mathrm{s}$ for every 5 years of life [52]. Studies of note include the Whitehall II, which measured carotid-femoral PWV in 3789 men and 1383 women free from cardiovascular disease, every 4 years [2]. Results showed an increase in arterial stiffness, with an exponential increase in the progression with age [2]. Similar results were found in the SaridNIA study [107]. Increasing arterial stiffness may be due to a disturbance in the regulatory pathways involved in sustaining the arterial extracellular matrix [107]. For example, upregulation of the renin-angiotensin system results in an increase in activation of pro-inflammatory pathways and thus increased destruction of the vessel wall [107]. Furthermore, fragmentation of elastin fibres, alongside increased collagen production, results in reduced elasticity of the vessel wall and ultimately arterial stiffness [107]. Chronic hypoperfusion as a result of narrowed, less responsive vessels leads to microvascular ischaemia, which can result in brain atrophy and tissue damage over time $[43,45]$. The changes with age in PWV and central pulse pressure result in a reduced ability of the larger cerebral vessels to dampen pulsatile energy, which is transmitted directly to the smaller brain vasculature [52]. This combined with elevated vascular risk factors (e.g. hypertension, raised cholesterol), results in progressive damage to smaller vessels [52]. Small vessel disease can lead to chronic conditions such as vascular dementia, as well as acute incidents such as lacunar infarctions [52].

In addition to arterial stiffness, endothelial dysfunction is thought to be a significant contributor to cerebrovascular ageing and results from a reduction in nitric oxide (NO) availability, oxidative stress and chronic inflammation [108]. Endothelial cells are important in the regulation of vascular tone, and thus CBF, through the release of $\mathrm{NO}$ (a potent vasodilator) [50]. Furthermore, endothelial dysfunction may contribute to age-related disorders, such as dementia [50, $130]$, and can be improved with healthy lifestyle interventions [108].

The brain relies on CBF to sustain neuronal metabolism due to its high level of metabolic activity and limited capacity for storage [118]. The cerebrovasculature has a low inherent ability to cope with the high volume blood supply, making the brain vulnerable to changes in CBF [118]. Therefore, cerebral autoregulation $(\mathrm{CA})$ is important in sustaining a relatively constant $\mathrm{CBF}$ despite changes in arterial blood pressure
(ABP) [53]. Lassen described a segmental autoregulatory curve to conceptualise CA (Fig. 1) [53]. The curve describes a lower limit, below which there is a risk of hypoperfusion, a plateau phase in which changes in perfusion pressure are unlikely to cause damage, and an upper limit above which risks structural damage to the brain [53]. The Rotterdam study followed 1730 participants aged over 50 years without cardiovascular disease and found CBF declined with normal ageing and to a higher degree in men than women [103]. This reduction in CBF can be associated with a decrease in cerebral metabolic rate, affecting neuronal activities in the brain [55].

Neural processing is highly resource intensive, requiring $20 \%$ of the body's resting energy demands, making the brain one of the most metabolically active organs in the body [57, 117]. Under normal physiological conditions, CBF is tightly coupled to neuronal activity through the process of NVC [32], ensuring rising metabolic needs are met during times of increased neuronal activity $[23,57,117]$. NVC must occur in a coordinated fashion, ensuring that $\mathrm{CBF}$ is increased in a region-specific manner, diverting flow to areas involved with specific neuronal processes and functions (functional hyperaemia) $[32,117]$. This coordination is achieved through the neurovascular unit, which is formed structurally and functionally by neuronal, vascular endothelial, smooth muscle and supporting cells (astrocytes, glia) [32, 117, 137].

The framework for this review is based on the theory that the structural and cellular changes outlined above will result in functional changes in vascular physiology. In particular, CA and NVC are two functional vascular processes critical for the

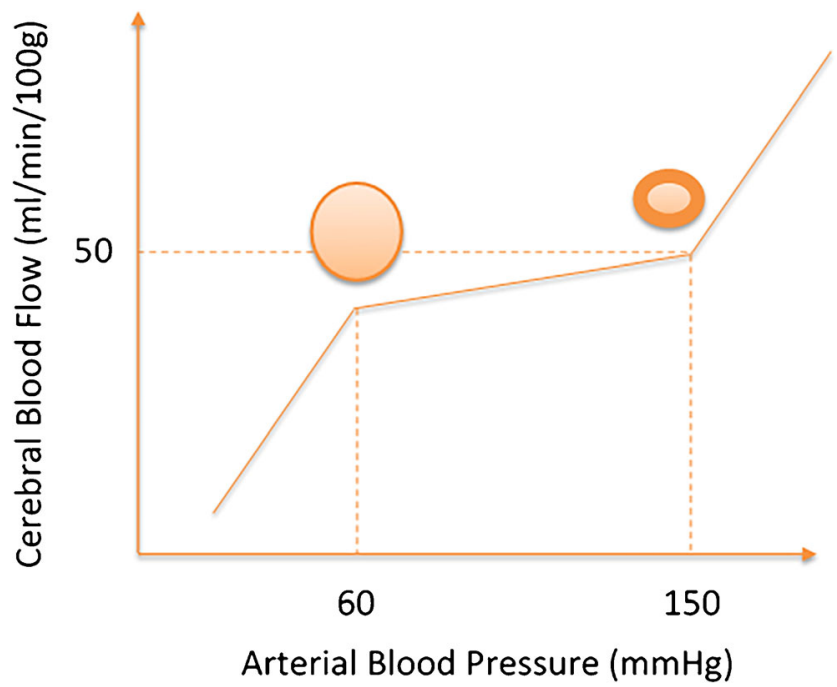

Fig. 1 Schematic representation of the concept of static CA as originally proposed by Lassen [53], showing the lower and upper mean blood pressure limits of CA. Arterioles are maximally vasodilated at and below the lower limit and maximally constricted at the upper limit, as represented by the cross sections in the diagram. Recent studies have suggested that the regions where static CA is active show a slope greater than zero and that this could be different for increases or reductions in mean blood pressure [77] 
maintenance of adequate brain function. Figure 2 conceptualises the framework and basis of age-related vascular changes leading to impairments in vascular function. This review will now focus on these two key processes in further detail below.

\section{Neurovascular coupling}

NVC is mediated by three main mechanisms [97, 113]. Firstly, metabolic activity generates vasoactive metabolites (e.g. $\mathrm{CO}_{2}$, lactate) which provide "feedback" resulting in vessel dilation and thus increased flow [38, 40, 97, 113, 137]. However, a "feedforward" model has also been proposed, whereby neuronal signalling drives NVC through the release of mediators resulting from synaptic activity (e.g. $\mathrm{K}+, \mathrm{NO})$ and prostanoids [40]. Recently, astrocytes have been found to be sensitive to local changes in oxygen, $\mathrm{CO}_{2}$, lactate, $\mathrm{pH}$ and neurotransmitter release as a result of metabolic activity and may act as an intermediary between tissue pressure and neural activity through mechanosensors $[38,40]$. Shear wall stress occurs when flow increases through a vessel, applying a physical stress to the vessel wall, resulting in the release of vasoactive mediators, such as nitric oxide, resulting in vasodilation [113]. Finally, the autonomic nervous system is able to constrict and dilate arteriolar smooth muscle by altering the level of sympathetic and parasympathetic tone, respectively [97, $113,137]$. Glutamate stimulates neurones and astrocytes to release chemical mediators (i.e. NO, prostaglandin, potassium), which act on vascular smooth muscle to cause vasodilation [39, 40,67]. Figure 3 shows the integration of feedforward and feedback mechanisms proposed in NVC processes resulting in increased $\mathrm{CBF}$.

A recent development in our understanding of NVC has been the identification of pericytes, which are located in close proximity to capillaries in the brain [35]. Pericytes are contractile cells that may have the ability to regulate capillary vessel diameter and thus influence flow at the capillary bed [35]. However, in vivo studies are less clear about the role of pericytes in modulating NVC, and their role may be more to re-distribute flow at a local level [39].

A number of age-related changes occur in NVC processes, but the shift from normal age-related change to that associated with age-related diseases (e.g. Alzheimer's dementia, Parkinson's disease) is less well understood. Thus, understanding the changes that occur under normal ageing, and how these may subsequently evolve into age-related disorders, is imperative to develop effective treatments for the maintenance and promotion of healthy brain ageing.

\section{Measurement of NVC in humans}

NVC can be measured indirectly using a number of noninvasive neuroimaging techniques [39], where individuals are stimulated using visual, auditory, motor, sensory or cognitive paradigms to elicit a rise in metabolic activity $[33,115]$. Traditionally, functional magnetic resonance imaging (MRI) used blood oxygen level-dependent (BOLD) signal to
Fig. 2 The vascular changes and mechanisms seen with ageing that may lead to functional alterations in cerebral autoregulation (CA) and neurovascular coupling (NVC). NO, nitric oxide; $\mathrm{CA}$, cerebral autoregulation; NVC, neurovascular coupling

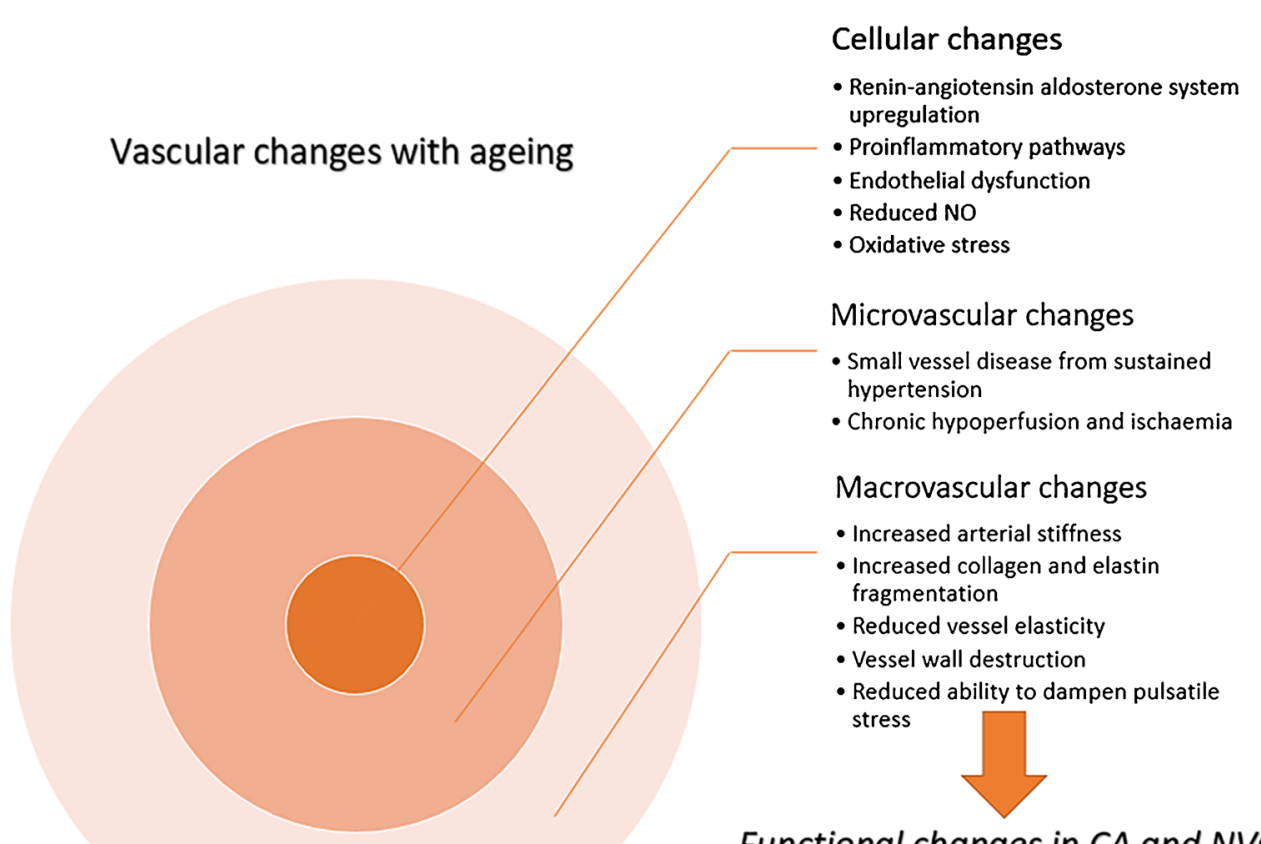

Functional changes in CA and NVC 


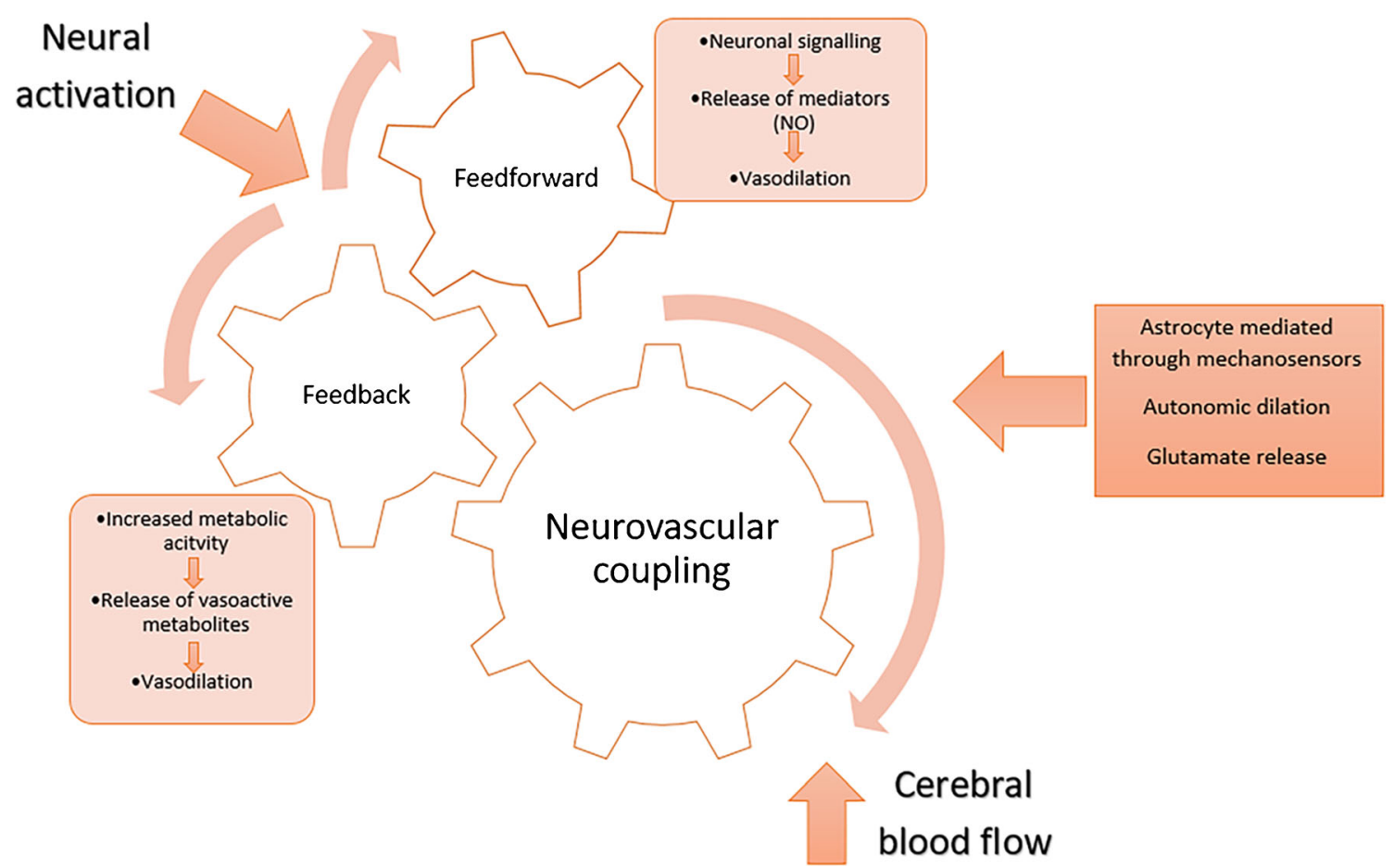

Fig. 3 Feedforward and feedback mechanisms that may result in NVC-mediated increases in cerebral blood flow following neural activation. NO, nitric oxide

measure changes in the concentration of deoxygenated haemoglobin (dexoyHb) in response to cognitive stimulation, as a proxy for metabolic activity $[11,33,39]$. Where participants are cognitively stimulated, deoxyHb levels rise initially as the limited oxygen stores are consumed [25,33]. This is followed by a fall in deoxyHb concentration as NVC processes work to deliver oxygen, usually in excess of the amount which has been utilised [33]. However, BOLD fMRI is limited to measurement of oxygen concentration and cannot provide any information on the haemodynamics of the NVC response [11, 33]. Arterial spin labelling (ASL) fMRI, which magnetically labels water as an endogenous tracer, rather than measuring changes in blood oxygenation, does allow for quantification of flow measurements [11, 33, 37]. However, widespread adoption of ASL techniques has been hampered by low signal to noise ratio, and lack of standardisation in methods and techniques between centres, although recent efforts have been made to overcome these limitations [33, 37]. BOLD and ASL fMRI have an excellent spatial resolution (1$2 \mathrm{~mm}$ ) but lack the temporal resolution (1-2 s vs. $5 \mathrm{~ms}$ ) of alternatives, such as TCD [39]. Furthermore, BOLD fMRI is susceptible to misinterpretation in older adults given a number of age-related effects on the signal including increased signal variability [46], lower resting CBF [23], reduced grey matter volume and altered vascular structure and function [46]. Importantly, baseline measurements prior to task activation are important in studies of ageing. Given that older adults are more likely to have lower resting flow measurements, task-activated responses can appear greater compared to younger adults as a result of lower resting values, if baseline differences are not accounted for [25]. ASL measurements can be useful in this setting to clarify the difference in resting and activated flow states that can only be measured by change from baseline using other techniques (e.g. BOLD-MRI) [25]. Correction for partial volume effects is not undertaken by all studies and may also account for differences in hyperand hypoactivation [46].

NIRS measures the relative fluctuations of deoxyHb and oxygenated haemoglobin (oxyHb) to determine changes in CBF mediated via NVC processes [23]. Where participants are cognitively stimulated, the relative concentration of oxyHb will rise as $\mathrm{CBF}$ increases and the change in oxyHb/ deoxyHb can be measured through their different absorption wavelengths in the infrared spectra $(\sim 700-900 \mathrm{~nm})[23,49]$. Whilst NIRS can measure the change in oxygenation, it cannot directly measure the change in CBF [23]. Furthermore, NIRS has a limited penetration depth and thus can only measure superficial and not deeper cortical changes in response to stimulation [49].

TCD uses ultrasound to measure changes in $\mathrm{CBF}$ velocity (CBFv) following cognitive stimulation $[6,115]$. $\mathrm{CBFv}$ is measured as a proxy for $\mathrm{CBF}$ on the assumption that the vessel diameter remains relatively constant under small fluctuations in $\mathrm{CO}_{2}$ and blood pressure $[15,85]$. TCD can be used to measure NVC in the middle, anterior and posterior cerebral arteries (MCA, ACA and PCA, respectively) [85]. Thus, as TCD measure changes in larger cerebral vessels, it has excellent temporal, but limited spatial, resolution [85]. Similar to 
ASL, TCD is advantageous in its ability to provide a measure of haemodynamic changes, rather than relying on indirect measures of changes in oxy/deoxyHb. In the context of ageing, NIRS and TCD are advantageous in their portability, relative lower cost and use in patients with pacemakers and metal implants $[23,49]$.

Dynamic retinal vessel analysis (DVA) is a relatively newer technique which examines the change in retinal arteriolar vessel diameter following light exposure using a retinal camera [57]. Retinal vessels are both structurally and functionally similar to their cerebral counterparts, but non-invasive imaging of the retinal vessels can be achieved relatively easily and cheaply when compared to cerebral vessel imaging [57]. NVC processes in the retinal vessels can be measured following light stimulation and invoke similar processes to those occurring in cerebral tissue (glial cell activation, vasodilation) [57]. Furthermore, retinal vessels are susceptible to similar pathological processes as cerebral vessels and abnormalities in the retinal vasculature are predictive of cerebrovascular pathology (stroke, vascular dementia) $[24,57]$.

\section{NVC in ageing}

Studies have found conflicting effects of ageing on NVC processes. We consider these under three major headings: hyperactivation, neutral activation and hypoactivation. Table 1 and Fig. 4 summarise the characteristics, techniques and major findings of the studies in this review.

\section{Hyperactivation}

In a recent study by this group, TCD-measured task activation using memory and visuospatial cognitive paradigms resulted in increased $\mathrm{CBFv}$ responses, relative to baseline, in older compared to younger individuals [7]. This is in keeping with a previous TCD study of varying cognitive exercises [26]. Similarly, Sorond et al. found greater TCD-measured CBFv responses in older adults, in response to word-stem completion and visual search tasks compared to younger adults [112]. These findings were not task specific, but the regional activations seen in the younger group were lost in the older group for the word-stem completion task [112]. Csipo et al. demonstrated larger NIRS-measured haemodynamic responses to finger tapping in the contralateral motor and prefrontal cortices in older adults [23]. Furthermore, the deoxyHb signal was delayed and reduced (effectivity of washout), with loss of the early oxyHb signal which is thought to represent mental preparation for the activity [23]. Jamardar recently demonstrated hyperactivation at four levels of difficulty in a working memory and task-switching paradigms in older adults using fMRI [42]. Hyperactivation may be a compensatory mechanism, where increased neuronal recruitment can maintain cognitive performance in line with that of healthy younger adults [106]. This is supported by a number of cognitive theories of ageing including the hemispheric asymmetry reduction in older adults (HAROLD) [8] and compensatory-related utilisation of neural circuits hypothesis (CRUNCH) [106].

\section{Hypoactivation}

In contrast to the findings outlined above, Kannurpatti et al. found reduced BOLD-MRI NVC responses to cognitive and motor paradigms in older adults [46]. Reduction in grey matter volume accounted for the majority of this difference, but age-related vascular and neural changes differentially affected the responses to motor and cognitive paradigms, respectively [46]. In a review of TCD-measured task activation by Stroobants and Vingerhoets, one study demonstrated lower $\mathrm{CBFv}$ responses to motor and cognitive paradigms, with less lateralisation $[80,115]$. In three studies of visually evoked TCD-measured CBFv responses in the PCA, older adults showed lower $\mathrm{CBFv}$ responses to visual stimulus compared to younger adults $[30,76,138]$. Furthermore, the calculation of an index of NVC (evoked flow/evoked potential) showed a reduction in NVC responses in the older group [138]. This is in keeping with two BOLD-MRI studies, demonstrating reduced neuronal and haemodynamic responses [29, 132], and delayed time to peak response and return to baseline [132]. Using dynamic retinal vessel analysis, ageing was associated with a $45-51 \%$ reduction in retinal vessel response to light stimulation $[51,57]$. This reduction may be as a result of endothelial dysfunction, which has been shown to occur with ageing, resulting in a reduced ability of vessels to increment flow appropriately when stimulated [57, 60,117]. Finally, in a NIRS-measured study using a working memory task at two difficulty levels, oscillations at low and very low frequencies were reduced in older compared to younger adults during task performance [129]. In younger adults only, this increased with cognitive load [129].

\section{Neutral activation}

Contrary to the studies described above which demonstrated hyper- and hypoactivation of NVC responses in ageing, a number of studies have not been able to demonstrate any discernible effects of ageing on NVC. In a study of 29 healthy older adults aged over 60 and 29 younger adults aged under 30, Stefanidis et al. did not identify age-related differences in CBFV response to ten blocks of $40 \mathrm{~s}$ of reading [114]. Similarly, Madureira et al. found no differences in TCD-measured NVC using a working memory task [61]. Grinband et al. found no differences in BOLD-MRI measured responses to two audio-visual tasks between older and younger adults [34]. The authors concluded that age-related changes in the haemodynamic response activation 


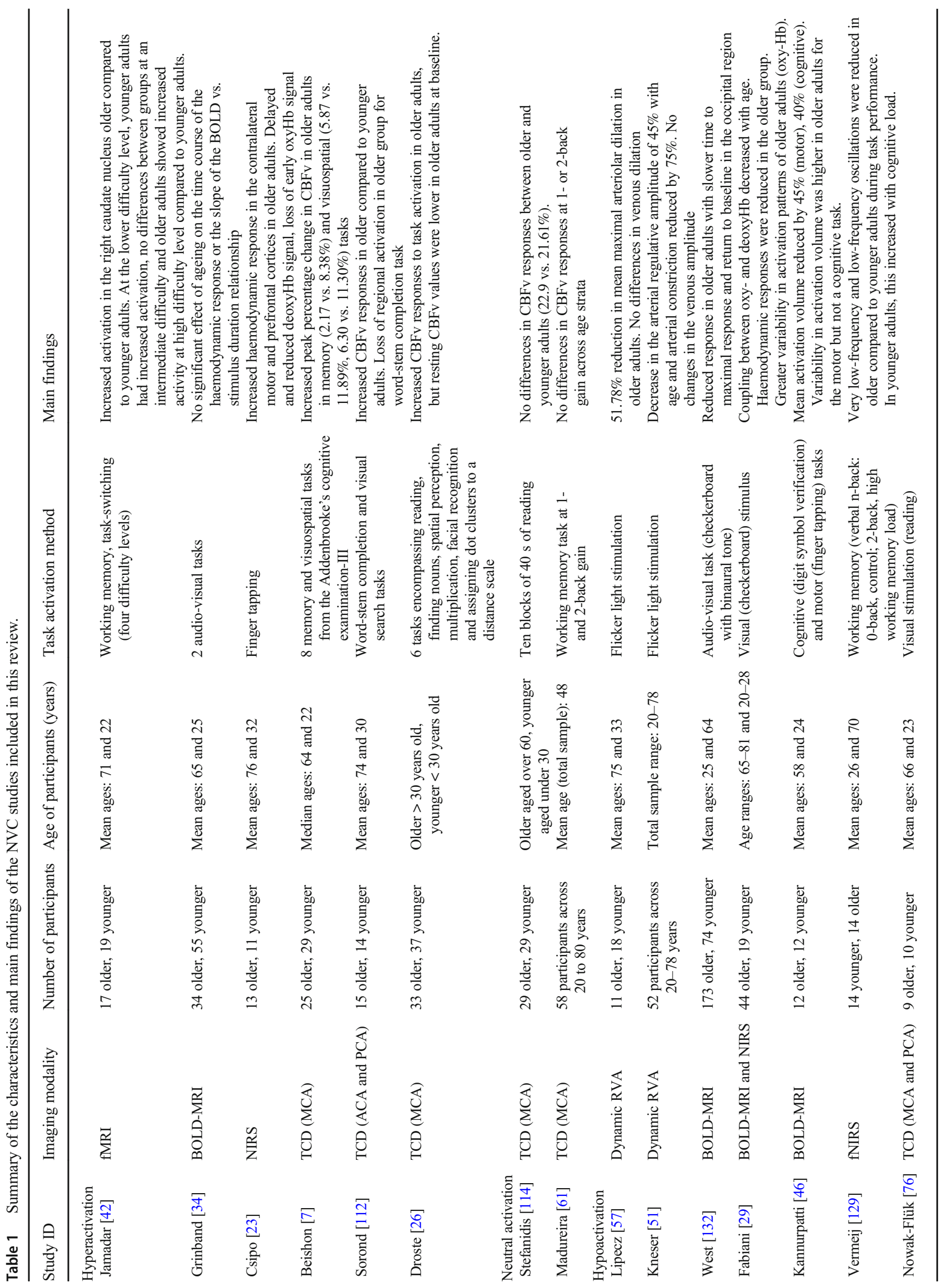




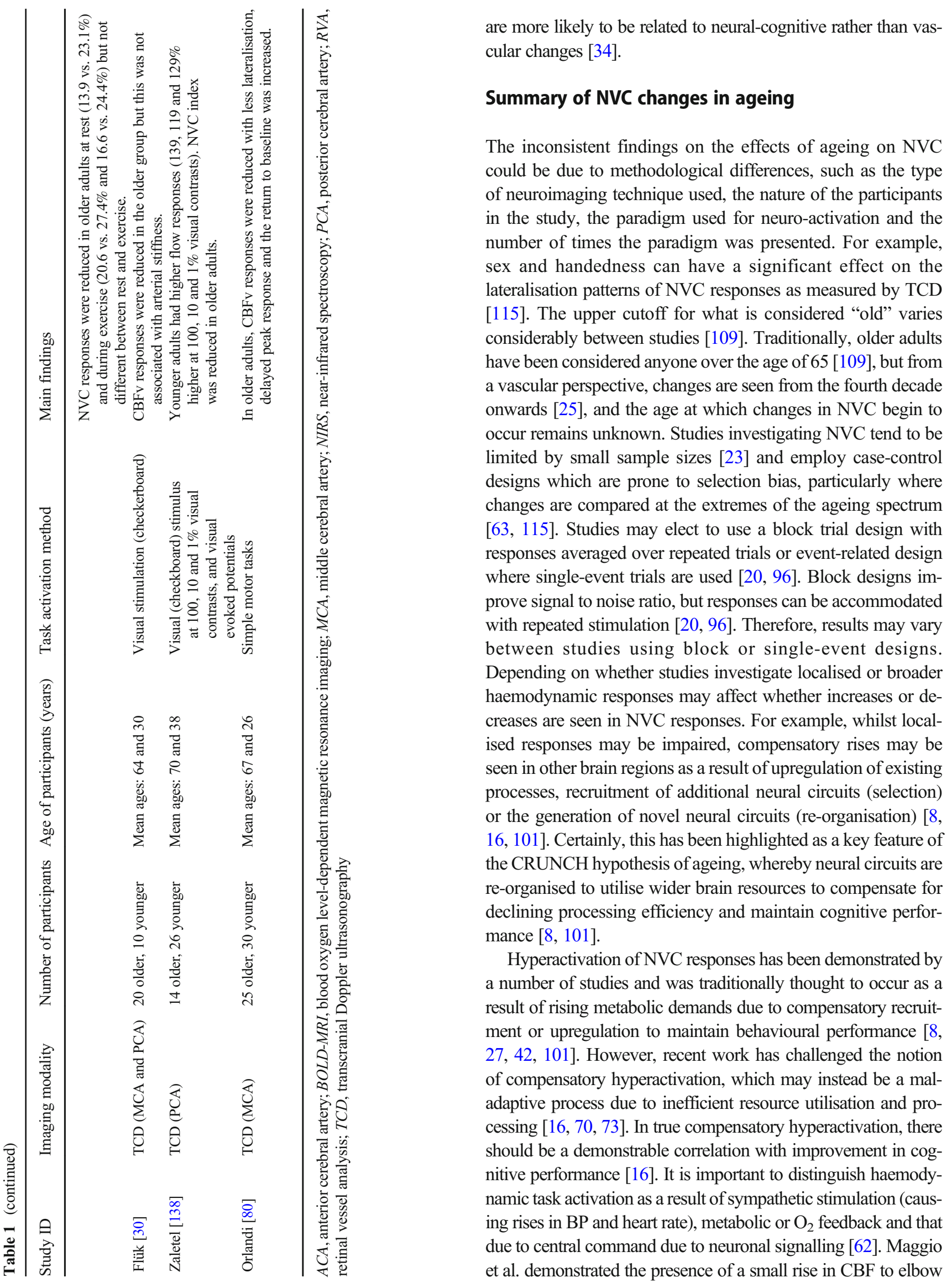




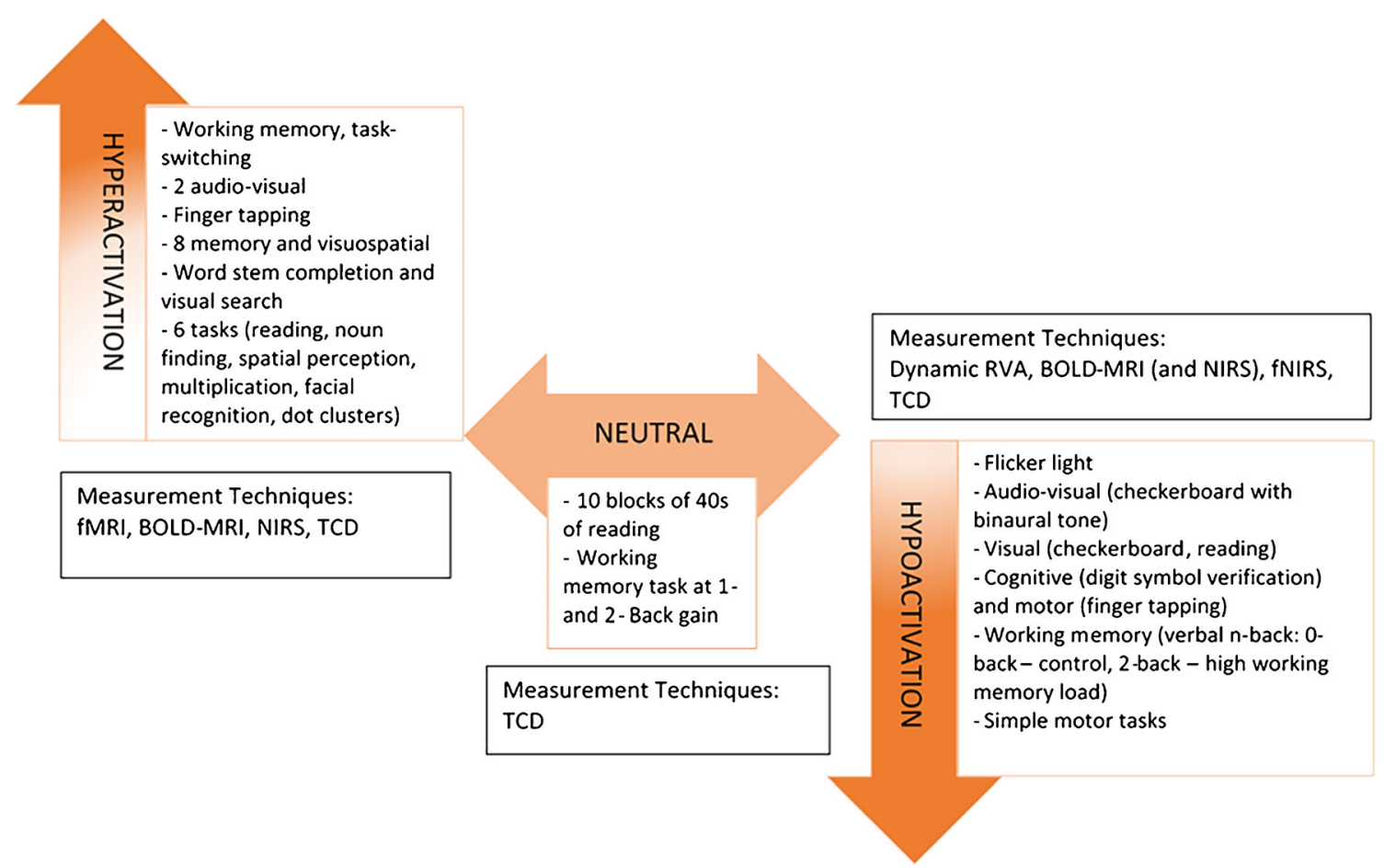

Fig. 4 Tasks showing changes in NVC responses in ageing using various measurement techniques. fMRI, functional magnetic resonance imaging; BOLD-MRI, blood oxygenation level-dependant magnetic resonance

flexion during hypercapnia despite $\mathrm{CBF}$ far in excess of the NVC demand as a result of the increased supply from $\mathrm{CO}_{2}$-induced vasodilation [62]. This finding suggests that central command through neuronal signalling may be driving the NVC response, rather than via a feedback mechanism from metabolic or $\mathrm{O}_{2}$ demand [62]. In support of this, a recent review identified up to $30 \%$ of the NVC response remains unaccounted for in terms of mechanistic pathways [38]. However, the effects of ageing on NVC in hyper- and hypocapnic states have not yet been investigated. Hyperactivation in response to cognitive stimulation is also seen in mild cognitive impairment (MCI) [5], where patients have an $80 \%$ chance of developing dementia over five years [95]. Thus, although hyperactivation may be present in cognitively healthy individuals, it may not represent a normal physiological adaptation to ageing. Longitudinal fMRI studies predicting cognitive decline from task activation have shown mixed results, with some demonstrating hyperactivation [134] and others demonstrating hypoactivation $[10,36,78,94]$ as protective of cognitive function. The differences in these findings are likely due to heterogeneity introduced by small sample sizes, inclusion of those with genetic risk factors (i.e. APOe4 allele), and the choice of cognitive paradigm [134]. Hypoactivation may occur in the context of vascular ageing, due to increasing arterial stiffness and reduced compliance, reducing the ability of arteries to rapidly dilate in response to stimulation $[25,29,137,138]$. Therefore, specific patterns of response may not always be "healthy" despite intact cognitive function and can be indicative of future cognitive impairment risk. Further work is required to imaging; NIRS, near-infrared spectroscopy; TCD, transcranial Doppler ultrasonography; fNIRS, functional near-infrared spectroscopy; RVA, retinal vessel analysis

investigate the relationship between neuroimaging features of ageing and future risk of cognitive decline to identify protective versus maladaptive haemodynamic ageing patterns.

According to the CRUNCH hypothesis, more cognitively challenging paradigms (i.e. episodic memory) are more likely to result in hypoactivation than less challenging paradigms (i.e. semantic memory), due to a ceiling at which compensation is no longer effective [101, 134]. Thus, hypo- or hyperactivation may be seen depending on the level of difficulty introduced by the cognitive paradigm [42]. In addition, the type of cognitive paradigm could also be important, given that ageing disproportionately affects the speed of processing, working memory and executive functioning [71]. Thus, tasks involving these elements may result in hyperactivation, whereas those less affected by ageing may result in neutral or hypoactivation. In Table 1, the majority of tasks demonstrating hypoactivation used a visual stimulus, focusing on the posterior cortex, rather than more complex higher cortical functions. However, this notion was recently challenged by Jamadar, who demonstrated hyperactivation in older adults at all levels of task difficulty [42], exceeding that which was tested in the original CRUNCH model [101]. For future studies, a range of paradigms and difficulties may be required that test different aspects of cognitive function but also different functional and structural brain regions. In this regard, combining neuroimaging techniques with good spatial and temporal resolution will 
provide important insights into the physiological changes that occur in NVC in ageing, and whether there is region specific or time dependent [23].

\section{Cerebral autoregulation}

\section{Relevance of haemodynamics and the healthy brain}

$\mathrm{CA}$ is a measure of haemodynamic integrity of myogenic mechanisms with co-existing metabolic and neurogenic components $[100,133]$. It allows the cerebral perfusion and brain tissue oxygenation to be buffered against BP changes [124]. In most studies of $\mathrm{CA}, \mathrm{CBF}$ has been measured using $\mathrm{CBFv}$ as a surrogate [56].

CA can be expressed as a static or dynamic mechanism. Static CA regulates CBF over long-term changes in cerebral perfusion pressure (CPP) (minutes to hours) [92]. Cerebral vasculature may have the more efficient autoregulatory ability when mean arterial pressure (MAP) is increased than when decreased [77]. Static CA can be measured by manipulating blood pressure (BP) and measuring the autoregulatory response by the change in CBF. CA is intact if blood flow is maintained at or near the baseline level [121], where static CA demonstrates a nearly constant CBF for MAP changes from 60 to $150 \mathrm{mmHg}$ [84]. If a change in BP leads to a significant change in CBF, CA is impaired [121, 133]. Although the static approach can evaluate the overall effect (efficiency) of CA, it does not reflect the latency of the response and it is also very difficult to implement, due to the need to use vasoactive drugs to achieve stable changes in MAP $[1,121]$.

Dynamic $\mathrm{CA}(\mathrm{dCA})$ is the pressure-flow relationship seen during transient changes in mean arterial BP, over a period of seconds [1]. Measuring dynamic $\mathrm{CA}$ involves inducing rapid changes in MAP caused by BP manoeuvres such as the sudden release of compressed thigh blood pressure cuffs (as an autoregulatory stimulus) and comparing $\mathrm{BP}$ and $\mathrm{CBFV}$ during the autoregulatory response [121]. dCA measurement gives information about the latency, as well as efficiency and can be studied with a number of different manoeuvres to induce rapid changes in MAP [121].

\section{Introduction to cerebral haemodynamic indices in the healthy brain}

The dynamic relationship between mean BP and CBF (or CBFv) has been modelled in the time or frequency domain $[22,81,127]$, giving rise to a number of different parameters or indices that reflect the efficiency and/or latency of the CA response [22, 81, 127]. Examples of dCA indices obtained in the time domain are the correlation coefficient $\mathrm{Mx}$ or the autoregulatory index ARI. Frequency domain representation of the BP-CBFv relationship is often obtained with transfer function analysis (TFA), which generates measures of coherence, gain and phase, often used as indices of dCA efficiency $[22,127]$. Table 2 summarises the most common indices used to measure $\mathrm{dCA}$; for a more complete description of $\mathrm{dCA}$ indices, we direct the reader to a number of excellent reviews and papers $[19,54,59,84,104,105,110,125-127]$.

\section{Methods of assessing dCA in healthy individuals and association with ageing}

dCA can be assessed in healthy individuals by a variety of methods. These include manoeuvres to induce rapid changes in MAP, such as the thigh-cuff manoeuvre, hand-grip, squatstand or sit-to-stand protocols. Spontaneous fluctuations in MAP can also be used, normally in conjunction with TFA. Here we will give an overview of these methods with relevance to studies of ageing.

\section{TFA}

TFA is widely used across studies of autoregulation to allow the estimation of $\mathrm{dCA}$ parameters from spontaneous rather than induced BP fluctuations [127]. For research studies focusing on older participants, this is particularly advantageous as this can be better tolerated than the thigh-cuff and squatstand manoeuvre [4]. In a longitudinal study of ten subjects who were followed for 10 years, ARI measured by TFA was found to decrease, suggesting dCA became less efficient with age [13]. As measures were repeated in the same individuals, this study was able to overcome inter-subject variability that confounds studies of dCA [13, 104, 105]. Carey et al. used multiple methods (spontaneous, thigh-cuff release, Valsalva manoeuvre) to determine the ARI in older and younger adults [17]. Across all methods, there was no effect of age on ARI [17]. In a study of three age groups (20 young ( 24 years), 20 older ( $\sim 66$ years) and 18 older old ( $~ 78$ years)), only phase in the very-low-frequency range was higher in the younger compared to older but not older old adults [82]. The gain was increased in the high-frequency range of the older old compared to younger adults, but there were no other differences between other age groups [82]. Similarly, in a large database study of 129 adults (median age 57), the gain was significantly associated with age (gain increased with age) but not phase or ARI parameters [91]. In contrast to these findings, Vermeij et al. did not find any significant effect of age on NIRSmeasured phase and gain [129], and Teixeira et al. found no effect of age on TCD-measured phase and gain parameters [119].

\section{Thigh-cuff manoeuvre}

The thigh-cuff manoeuvre can be used to rapidly alter BP. Bilateral thigh cuffs are inflated to above systolic BP. 
Table 2 A summary of the most commonly measured indices for dCA

\begin{tabular}{|c|c|c|}
\hline dCA Index & Measurement & Interpretation \\
\hline ARI & $\begin{array}{l}\text { Measures response of CBF to rapid changes in BP } \\
\text { Second-order linear differential equation, with } 3 \\
\text { main coefficients that are then tabulated to } \\
\text { correspond to } 10 \text { different values of ARI [121] }\end{array}$ & $\begin{array}{l}\text { Range from } 0-9 \\
\text { Higher ARI = better autoregulation, } \\
\text { so faster return to baseline after } \\
\text { MAP increase } \\
\text { Healthy controls }=5 \pm 1\end{array}$ \\
\hline Mx, Mxa & $\begin{array}{l}\text { Measures dCA by calculating a time-average Pearson } \\
\text { correlation coefficient between slow fluctuations in } \\
\text { CBFV and CPP (Mx) or mean arterial BP (Mxa), } \\
\text { over a given time period }\end{array}$ & $\begin{array}{l}0 \text { or less suggests CA intact } \\
0.3-0.5 \text { suggests impaired } \mathrm{CA}\end{array}$ \\
\hline PRx & Correlation between slow-wave changes in MAP and ICP & $\begin{array}{l}\text { Coefficient ranging from }-1 \text { to }+1 \\
\text { Positive PRx indicates passive behaviour of } \\
\text { cerebral vessels, so reduced CA } \\
\text { Negative PRx indicates normally reactive } \\
\text { vascular bed, so intact CA }\end{array}$ \\
\hline RAP & $\begin{array}{l}\text { Index of CVR.A } \\
\text { CVR.A = BP/CBFV } \\
\text { It is the inverse of the regression slope of CBFV vs BP } \\
\text { The dynamic autoregulatory response occurs } \\
\text { through adjustments in RAP [87] }\end{array}$ & $\begin{array}{l}\text { More indicative of myogenic activity and } \\
\text { cerebrovascular resistance [88] }\end{array}$ \\
\hline RoR & $\begin{array}{l}\text { Measures the rate of change in CVR, which is } \\
\text { dependent on the change in } \mathrm{ABP} \\
\mathrm{RoR}=(\Delta \mathrm{CVR} / \Delta \text { time }) / \Delta \mathrm{ABP} \\
\text { Full restoration of } \mathrm{CBF} \text { where } \Delta \mathrm{CVR}=\Delta \mathrm{ABP}\end{array}$ & $\begin{array}{l}\text { Increasing RoR represents an increased per } \\
\text { second adjustment of the change in CVR to } \\
\text { fully compensate for the change in ABP [1] } \\
\text { Higher RoR = better autoregulation }\end{array}$ \\
\hline TFA gain & $\begin{array}{l}\text { Ratio of amplitude of oscillations in CBFv (output) } \\
\text { and the amplitude of oscillations in } \\
\text { MAP (input) at each frequency }\end{array}$ & $\begin{array}{l}\text { Higher gain = poorer autoregulation (i.e. reduced } \\
\text { ability of dCA to dampen the effects } \\
\text { of BP on CBFv) }\end{array}$ \\
\hline TFA phase & $\begin{array}{l}\text { Phase measures the delay of CBFv oscillations, } \\
\text { relative to corresponding oscillations in MAP } \\
\text { at each frequency [127]. }\end{array}$ & $\begin{array}{l}\text { Higher phase }=\text { better autoregulation (i.e. changes } \\
\text { in } \mathrm{CBFv} \text { recover faster than those in BP) [127] }\end{array}$ \\
\hline
\end{tabular}

$A R I$, autoregulation index; $P R x$, pressure reactivity index; $M x$, mean flow index; $R A P$, resistance area product; $R o R$, rate of regulation; $T F A$, transfer function analysis

Parameters are measured throughout, including MAP and TCD of the MCA. The thigh cuffs are then rapidly deflated, which induces step decreases in MAP [1]. The CBFv and BP values after the cuff release can be used to calculate ARI [1, 121]. Furthermore, change in CVR per second, in relation to the change in $\mathrm{BP}$, is referred to as the rate of the regulation (RoR) and can be used as an index of CA $[1,121]$. In a study of 27 subjects $\leq 40$ years and 27 subjects $\geq 55$ years, an association between increasing age and dCA was not seen during transient and induced BP stimuli [17]. Specific investigations of the cerebrovascular effects of the thigh-cuff manoeuvre in older adults have demonstrated a dominance of myogenic mechanisms, largely influenced by associated $\mathrm{EtCO}_{2}$ changes with components of the autonomic nervous system and baroreflex exerting concomitant effects [89].

\section{Hand-grip manoeuvre}

The hand-grip manoeuvre (HG) uses the contraction of forearm muscles to induce changes in $\mathrm{HR}, \mathrm{BP}$ and $\mathrm{CO}_{2}$ [99]. It causes changes in $\mathrm{CBF}$, possibly due to bilateral activation of cortical brain areas involved in muscle contraction and autonomic regulation [44]. However, the use of the handgrip manoeuvre to assess dCA assumes that the handgrip itself would not disturb dCA [48]. Jorgensen et al. found that there was not an increase in cerebral perfusion caused by the increase in BP induced by handgrip [44]. In addition, ARI is not constant during the hand-grip manoeuvre, with significant dips at the beginning and the end [86]. In a study by Carey et al. described above, there were no differences in ARI as measured by HG in older compared to younger adults [17]. In keeping with this finding, Bronzwaer et al. did not demonstrate a significant effect of ageing on $\mathrm{dCA}$ assessed by $\mathrm{HG}$ or lower body negative pressure [14].

\section{Squat-stand manoeuvre}

Large changes in BP can be produced from squatting from the standing position [9]. Birch et al. asked volunteers to perform cycles of squatting and standing, as indicated by a computer, which then allows changes in MCA velocity and dCA to be measured. They found that oscillations in BP led to induced oscillations in the MCA velocity, which may indicate functioning autoregulation [9]. In the squat-stand manoeuvre, there are 
relatively large changes in BP and hence, repeated squat-stand manoeuvres can be used to investigate the directional sensitivity of CA [90]. However, in the older population, squat-stand manoeuvres may not always be practical, with concomitant osteoarthritis, reduced exercise tolerance and comorbidities [82, 128]. Thus, many studies of older adults instead use the sit-to-stand manoeuvre, which also generates a transient response of CBF to changes in BP, if measurements are taken immediately after standing up [64, 128]. Recently, an older group of individuals (aged 50-71 years) as compared to a younger group (20-34 years) demonstrated lower ARI during maximal depth squats as compared to shallower squats - thereby suggesting less efficient dCA in older individuals during maximal depth squats as compared to rest or the shallower approach [4]. Similarly, reductions in NIRS-measured frontal cortex oxygenation were seen in 27 healthy older adults during sit-to-stand [65, 66], and highfrequency dCA was impaired in older adults during sit-to-stand [74]. However, in a study of repeated sit-to-stand manoeuvres in 58 participants ( 20 young, 20 older and 18 older old), there was a small reduction in phase and rise in gain with increasing age, but the authors conclude that dCA remains intact with ageing [82]. Similarly, a study of 136 adults between 21 and 89 years of age using sit-to-stand manoeuvres demonstrated higher gain at rest in older adults compared to younger and middle-aged adults but no difference in gain between age groups during sit-to-stand manoeuvres [135]. These findings were in keeping with that at Sorond et al., who also found no age-related changes in dCA with sit-to-stand in either the MCA or PCA but did demonstrate a smaller vasodilatory response in the PCA territory of older adults, suggesting it may be more vulnerable to hypoperfusion [111]. In two studies of head tilt to 30 and 70 degrees, neither showed a significant effect of ageing on cerebral haemodynamics, before, during or after tilting $[18,28]$. Finally, in a study by Lipsitz et al., older normotensive and hypertensive older adults both demonstrated intact dCA during a sit-to-stand manoeuvre, as measured by TFA gain and phase [58].

The various methods of assessing CA described above have provided mixed evidence of haemodynamic changes during ageing as assessed using non-respiratory paradigms. The majority of studies using sit-to-stand manoeuvres and resting TFA do not show any demonstrable effects of ageing on dCA, but there are some exceptions, specifically, the thighcuff manoeuvre [89] and the squat-stand measurement [4]. These conflicting findings may be due to methodological differences (resting vs induced and squat-stand vs sit-stand), and differences in the age ranges and population characteristics studied. Figure 5 summarises the changes in key dCA parameters with ageing.

\section{$\mathrm{PaCO}_{2}$, cerebral haemodynamics and brain ageing}

In the context of respiratory paradigms, a large study (150 participants) recently suggested that ageing is associated with lower $\mathrm{CBFv}$, greater cerebrovascular resistance and reduced vasoconstriction during hypocapnia, though increased vasodilatory responsiveness during hypercapnia [122]. Despite a longstanding acceptance that healthy ageing associates with lower $\mathrm{CBFv}[3,127]$, our confidence in concluding the specific behaviours of CA indices has been more contentious. In particular, previously mentioned haemodynamic parameters are pertaining to cerebrovascular tone (critical closing pressure- $\mathrm{CrCP}$ ), cerebrovascular resistance (RAP) [68, 69] and the ARI. Firstly, assessment of normative values and the influence of age within a large haemodynamic database demonstrated a lack of an association between increasing age and ARI during normocapnia $[17,91]$. Secondly, during normocapnia, older normotensive individuals have greater RAP than younger individuals, though, during posture change, there is a greater relative change in $\mathrm{CrCP}$ during upright posture in younger adults $[83,102]$. There is some suggestion of heightened sensitivity to postural changes through $\mathrm{CrCP}$ in younger compared to older individuals [102]. Thirdly, tangible changes in CVR are thought to occur in those over 50 years with the very old ( $>80$ years) seemingly exhibiting similar responses to those over 50 years of age; this is an important consideration when determining vascular neurological risk assessment [47].

Despite the contention generated through studies on the influence of ageing during normocapnic conditions, greater clarity has been gained through aligned hypocapnic
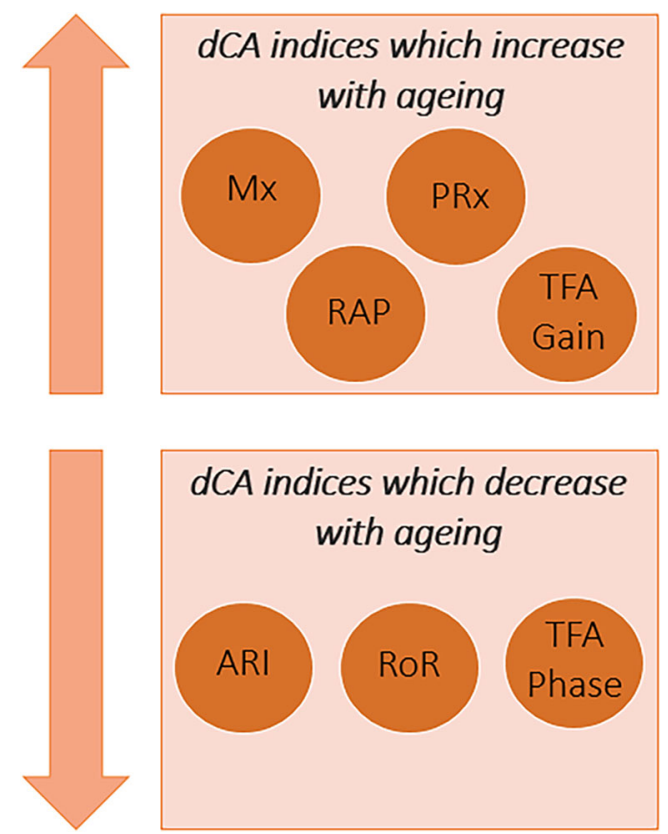

Fig. 5 Representation of how each dCA index changes with age. ARI, autoregulation index; PRx, pressure reactivity index; Mx, mean flow index; RAP, resistance area product; RoR, rate of regulation; TFA, transfer function analysis 
studies of the influence of $\mathrm{PaCO}_{2}$ changes and healthy ageing.

\section{Carbon dioxide and cerebral blood flow}

Carbon dioxide $\left(\mathrm{CO}_{2}\right)$ has a profound effect on mediating $\mathrm{CBF}$. The relationship between the partial pressure of carbon dioxide in arterial blood $\left(\mathrm{PaCO}_{2}\right)$ and $\mathrm{CBF}$ has been described as a sigmoid curve with lower and upper plateaus [116]. Elevated $\mathrm{PaCO}_{2}$ causes vasodilatation, increasing $\mathrm{CBF}$, and reduced $\mathrm{PaCO}_{2}$ causes vasoconstriction, decreasing CBF. This is thought to be due to increased $\mathrm{CO}_{2}$ leading to increased $[\mathrm{H}+]$ resulting in vascular smooth muscle relaxation [21]. This cerebral vasomotor reactivity (CVMR) is an important mechanism that regulates brain $\mathrm{pH}$ levels and affects respiratory central chemoreceptors. Additionally, there are thought to be other agents involved such as prostaglandins and nitric oxide $[12,93]$.

\section{CVMR and ageing}

As discussed, ageing is associated with lower $\mathrm{CBF}$ and $\mathrm{CBFv}$ $[3,139]$. However, research has yielded conflicting results regarding ageing and $\mathrm{CVRM}$ (i.e. response of $\mathrm{CBF}$ to changes to $\left.\mathrm{PaCO}_{2}\right)[31,41,136]$.

Zhu and colleagues found that older participants had lower $\mathrm{CBF}$ velocities and higher cerebrovascular resistance index in resting conditions [139]. Older participants had a reduced vasoconstrictor response to hypocapnia but increased vasodilatory response to hypercapnia [139]. This may suggest that ageing is associated with increased cerebral vasoconstrictor tone at rest, thus reducing the capacity of vessels to constrict in response to hypocapnia and increasing the capacity of vessels to dilate in response to hypercapnia. However, research remains inconsistent, with further studies finding no significant difference in CVRM or decreased response to hypercapnia [30, 72, 120]. In contrast to Zhu et al. [139], Galvin and colleagues found increased CVR to hypocapnia, correlated with increasing age, suggesting that increased CVR to hypocapnia may be contributory to the increased risk to cerebral ischaemia in ageing [31]. The varying response to $\mathrm{CO}_{2}$ may be related to the differences in study protocols employed in these studies, with variations in stimulus, protocols for CVR assessment and analysis. However, convergent findings do exist, though the key influencing parameter is debated. Minhas et al. (2019) did not demonstrate an alteration in ARI with $\mathrm{CO}_{2}$ change and increasing age, confirming prior large database findings [68]. However, an elevation in RAP, and not $\mathrm{CrCP}$, was seen during a hypocapnic stimulus in older ( $>50$ years) as compared to younger individuals $(\leq 49$ years) [68]. These findings align with Ogoh and colleagues who showed in older normotensive adults that RAP is elevated but not $\mathrm{CrCP}$ [79]. Specifically, the data suggest that RAP and $\mathrm{CrCP}$ maintain CVMR during hypocapnic challenge during healthy ageing.

\section{Summary}

Taken together, the majority of studies do not show a significant effect of ageing on dCA, despite differences in techniques and methodologies, populations and outcome measures. This poses a number of important questions. Particularly for the mechanisms of orthostatic hypotension, given that $\mathrm{dCA}$ remains intact during postural changes in many studies, but remains a significant contributor to falls and morbidity in the older populations. Importantly, the challenge provided by the unique influence of $\mathrm{CO}_{2}$ on the cerebral vasculature has arguably provided the greatest information, allowing us to differentiate the individual effects of CVMR, tone and autoregulation. Several studies have found a varying CVMR response to $\mathrm{CO}_{2}$ with both reduced and increased CVMR to hypercapnia and hypocapnia noted. Further research is required to elucidate the relationship between $\mathrm{CO}_{2}$ and $\mathrm{CBF}$ in the healthy brain and ageing. Developing a further understanding of the effects of ageing on the $\mathrm{CBF}$ dependence on $\mathrm{PaCO}_{2}$ in the healthy brain may help to differentiate agerelated variations from abnormal changes and thus help to identify those at higher risk of cerebrovascular disease.

Studies of ageing-related NVC changes have found mixed results of hyper-, hypo- or neutral activation. These differences are likely to be due to significant heterogeneity in neuroimaging techniques and methods, paradigm selection, presence of vascular ageing and genetic risks, and small sample sizes. Aligning methodologies and techniques through the establishment of guidelines for the conduct of studies investigating NVC will facilitate comparisons and meta-analyses of findings. Where possible, studies should use multiple imaging techniques to quantify flow measurements and provide information on the spatial and temporal nature of the response. Despite these limitations, alterations in NVC with ageing have been demonstrated and correlate with cognitive performance and can predict future dementia risk. Thus, understanding "healthy" ageing patterns in cerebral haemodynamics is imperative to promoting and maintaining brain health in later life.

Authors' contributions L.B. drafted the abstract and section on neurovascular coupling, R.C., M.K. and J.S.M. drafted the section on dynamic cerebral autoregulation and T.C. drafted the introduction. T.G.R., V.J.H. and R.B.P. provided comments and edits and contributed to the drafting of the final manuscript.

Funding L.B. is a Dunhill Medical Trust Research Training Fellow (RTF1806 27), M.K. is an NIHR Academic Clinical Fellow, J.S.M. is an NIHR Academic Clinical Lecturer and T.G.R. is an NIHR Senior Investigator. 


\section{Compliance with ethical standards}

Conflict of interest The authors declare that they have no conflicts of interest.

Open Access This article is licensed under a Creative Commons Attribution 4.0 International License, which permits use, sharing, adaptation, distribution and reproduction in any medium or format, as long as you give appropriate credit to the original author(s) and the source, provide a link to the Creative Commons licence, and indicate if changes were made. The images or other third party material in this article are included in the article's Creative Commons licence, unless indicated otherwise in a credit line to the material. If material is not included in the article's Creative Commons licence and your intended use is not permitted by statutory regulation or exceeds the permitted use, you will need to obtain permission directly from the copyright holder. To view a copy of this licence, visit http://creativecommons.org/licenses/by/4.0/.

\section{References}

1. Aaslid R, Lindegaard KF, Sorteberg W, Nornes H (1989) Cerebral autoregulation dynamics in humans. Stroke 20:45-52

2. Ahmadi-Abhari S, Sabia S, Shipley MJ, Kivimäki M, SinghManoux A, Tabak A, McEniery C, Wilkinson IB, Brunner EJ (2017) Physical activity, sedentary behavior, and long-term changes in aortic stiffness: the Whitehall II Study. J Am Heart Assoc 6. https://doi.org/10.1161/jaha.117.005974

3. Bakker SL, de Leeuw FE, den Heijer T, Koudstaal PJ, Hofman A, Breteler MM (2004) Cerebral haemodynamics in the elderly: the rotterdam study. Neuroepidemiology 23:178-184. https://doi.org/ 10.1159/000078503

4. Batterham AP, Panerai RB, Robinson TG, Haunton VJ (2020) Does depth of squat-stand maneuver affect estimates of dynamic cerebral autoregulation? Phys Rep 8:e14549. https://doi.org/10. 14814/phy2.14549

5. Beishon L, Haunton VJ, Panerai RB, Robinson TG (2017) Cerebral hemodynamics in mild cognitive impairment: a systematic review. J Alzheimers Dis 59:369-385. https://doi.org/10. 3233/jad-170181

6. Beishon LC, Williams CAL, Panerai RB, Robinson TG, Haunton VJ (2017) The assessment of neurovascular coupling with the Addenbrooke's cognitive examination: a functional transcranial Doppler ultrasonographic study. J Neurophysiol jn.00698.2017: 1084-1094. https://doi.org/10.1152/jn.00698.2017

7. Beishon L, Minhas JS, Patrick K, Shanmugam I, Williams CAL, Panerai RB, Robinson TG, Haunton VJ (2018) The effects of healthy ageing on cerebral blood flow responses to cognitive testing. Curr Aging Sci 11:226-235. https://doi.org/10.2174/ 1874609812666190131165310

8. Berlingeri M, Danelli L, Bottini G, Sberna M, Paulesu E (2013) Reassessing the HAROLD model: is the hemispheric asymmetry reduction in older adults a special case of compensatory-related utilisation of neural circuits? Exp Brain Res 224:393-410. https:// doi.org/10.1007/s00221-012-3319-x

9. Birch AA, Dirnhuber MJ, Hartley-Davies R, Iannotti F, NeilDwyer G (1995) Assessment of autoregulation by means of periodic changes in blood pressure. Stroke 26:834-837. https://doi. org/10.1161/01.str.26.5.834

10. Bookheimer SY, Strojwas MH, Cohen MS, Saunders AM, Pericak-Vance MA, Mazziotta JC, Small GW (2000) Patterns of brain activation in people at risk for Alzheimer's disease. N Engl J
Med 343:450-456. https://doi.org/10.1056/ nejm200008173430701

11. Borogovac A, Asllani I (2012) Arterial spin labeling (ASL) fMRI: advantages, theoretical constrains and experimental challenges in neurosciences. Int J Biomed Imaging 2012:1-13. https://doi.org/ $10.1155 / 2012 / 818456$

12. Brian Johnny E (1998) Carbon dioxide and the cerebral circulation. Anesthesiology 88:1365-1386

13. Brodie FG, Panerai RB, Foster S, Evans DH, Robinson TG (2009) Long-term changes in dynamic cerebral autoregulation: a 10 years follow up study. Clin Physiol Funct Imaging 29:366-371. https:// doi.org/10.1111/j.1475-097X.2009.00880.x

14. Bronzwaer AGT, Verbree J, Stok WJ, Daemen M, van Buchem MA, van Osch MJP, van Lieshout JJ (2017) Aging modifies the effect of cardiac output on middle cerebral artery blood flow velocity. Phys Rep 5:e13361. https://doi.org/10.14814/phy2.13361

15. Brothers RM, Zhang R (2016) CrossTalk opposing view: the middle cerebral artery diameter does not change during alterations in arterial blood gases and blood pressure. J Physiol 594:4077-4079. https://doi.org/10.1113/jp271884

16. Cabeza R, Albert M, Belleville S, Craik FIM, Duarte A, Grady CL, Lindenberger U, Nyberg L, Park DC, Reuter-Lorenz PA, Rugg MD, Steffener J, Rajah MN (2018) Maintenance, reserve and compensation: the cognitive neuroscience of healthy ageing. Nat Rev Neurosci 19:701-710. https://doi.org/10.1038/s41583018-0068-2

17. Carey BJ, Eames PJ, Blake MJ, Panerai RB, Potter JF (2000) Dynamic cerebral autoregulation is unaffected by aging. Stroke 31:2895-2900. https://doi.org/10.1161/01.str.31.12.2895

18. Carey BJ, Panerai RB, Potter JF (2003) Effect of aging on dynamic cerebral autoregulation during head-up tilt. Stroke 34:18711875. https://doi.org/10.1161/01.STR.0000081981.99908.F3

19. Chacón M, Jara JL, Panerai RB (2014) A new model-free index of dynamic cerebral blood flow autoregulation. PLoS One 9: e108281. https://doi.org/10.1371/journal.pone.0108281

20. Chee MW, Venkatraman V, Westphal C, Siong SC (2003) Comparison of block and event-related fMRI designs in evaluating the word-frequency effect. Hum Brain Mapp 18:186-193. https://doi.org/10.1002/hbm.10092

21. Cipolla M (2009) The cerebral circulation. Chapter 5, Control of Cerebral Blood Flow, Morgan \& Claypool Life Sciences, San Rafael. Available from: https://www.ncbi.nlm.nih.gov/books/ NBK53082.

22. Claassen JA, Meel-van den Abeelen AS, Simpson DM, Panerai RB (2016) Transfer function analysis of dynamic cerebral autoregulation: a white paper from the International Cerebral Autoregulation Research Network. J Cereb Blood Flow Metab 36:665-680. https://doi.org/10.1177/0271678x15626425

23. Csipo T, Mukli P, Lipecz A, Tarantini S, Bahadli D, Abdulhussein O, Owens C, Kiss T, Balasubramanian P, Nyul-Toth A, Hand RA, Yabluchanska V, Sorond FA, Csiszar A, Ungvari Z, Yabluchanskiy A (2019) Assessment of age-related decline of neurovascular coupling responses by functional near-infrared spectroscopy (fNIRS) in humans. Geroscience 41:495-509. https://doi.org/10.1007/s11357-019-00122-x

24. de Jong FJ, Schrijvers EM, Ikram MK, Koudstaal PJ, de Jong PT, Hofman A, Vingerling JR, Breteler MM (2011) Retinal vascular caliber and risk of dementia: the Rotterdam study. Neurology 76: 816-821. https://doi.org/10.1212/WNL.0b013e31820e7baa

25. D'Esposito M, Deouell LY, Gazzaley A (2003) Alterations in the BOLD fMRI signal with ageing and disease: a challenge for neuroimaging. Nat Rev Neurosci 4:863-872. https://doi.org/10.1038/ nrn1246

26. Droste DW, Harders AG, Rastogi E (1989) A transcranial Doppler study of blood flow velocity in the middle cerebral arteries 
performed at rest and during mental activities. Stroke 20:10051011. https://doi.org/10.1161/01.STR.20.8.1005

27. Dumas JA (2015) What is normal cognitive aging? Evidence from task-based functional neuroimaging. Curr Behav Neurosci Rep 2: 256-261. https://doi.org/10.1007/s40473-015-0058-X

28. Edlow BL, Kim MN, Durduran T, Zhou C, Putt ME, Yodh AG, Greenberg JH, Detre JA (2010) The effects of healthy aging on cerebral hemodynamic responses to posture change. Physiol Meas 31:477-495. https://doi.org/10.1088/0967-3334/31/4/002

29. Fabiani M, Gordon BA, Maclin EL, Pearson MA, BrumbackPeltz CR, Low KA, McAuley E, Sutton BP, Kramer AF, Gratton G (2014) Neurovascular coupling in normal aging: a combined optical, ERP and fMRI study. Neuroimage 85(Pt 1):592607. https://doi.org/10.1016/j.neuroimage.2013.04.113

30. Flück D, Beaudin A, Steinback C, Kumarpillai G, Shobha N, McCreary C, Peca S, Smith E, Poulin M (2014) Effects of aging on the association between cerebrovascular responses to visual stimulation, hypercapnia and arterial stiffness. Front Physiol 5. https://doi.org/10.3389/fphys.2014.00049

31. Galvin SD, Celi LA, Thomas KN, Clendon TR, Galvin IF, Bunton RW, Ainslie PN (2010) Effects of age and coronary artery disease on cerebrovascular reactivity to carbon dioxide in humans. Anaesth Intensive Care 38:710-717. https://doi.org/10.1177/ $0310057 \times 1003800415$

32. Girouard H, Iadecola C (2006) Neurovascular coupling in the normal brain and in hypertension, stroke, and Alzheimer disease. J Appl Physiol 100:328-335. https://doi.org/10.1152/ japplphysiol.00966.2005

33. Glover GH (2011) Overview of functional magnetic resonance imaging. Neurosurg Clin N Am 22:133-139. https://doi.org/10. 1016/j.nec.2010.11.001

34. Grinband J, Steffener J, Razlighi QR, Stern Y (2017) BOLD neurovascular coupling does not change significantly with normal aging. Hum Brain Mapp 38:3538-3551. https://doi.org/10.1002/ hbm. 23608

35. Hamilton N, Attwell D, Hall C (2010) Pericyte-mediated regulation of capillary diameter: a component of neurovascular coupling in health and disease. Front Neuroenerg 2. https://doi.org/10.3389/ fnene. 2010.00005

36. Hantke N, Nielson KA, Woodard JL, Breting LMG, Butts A, Seidenberg M, Carson Smith J, Durgerian S, Lancaster M, Matthews M, Sugarman MA, Rao SM (2013) Comparison of semantic and episodic memory BOLD fMRI activation in predicting cognitive decline in older adults. J Int Neuropsychol Soc 19:11-21. https://doi.org/10.1017/S1355617712000951

37. Hernandez-Garcia L, Lahiri A, Schollenberger J (2019) Recent progress in ASL. NeuroImage 187:3-16. https://doi.org/10.1016/ j.neuroimage.2017.12.095

38. Hosford PS, Gourine AV (2019) What is the key mediator of the neurovascular coupling response? Neurosci Biobehav Rev 96: 174-181. https://doi.org/10.1016/j.neubiorev.2018.11.011

39. Huneau C, Benali $H$, Chabriat $H$ (2015) Investigating human neurovascular coupling using functional neuroimaging: a critical review of dynamic models. Front Neurosci 9:467. https://doi.org/ $10.3389 /$ fnins. 2015.00467

40. Iadecola $C$ (2017) The neurovascular unit coming of age: a journey through neurovascular coupling in health and disease. Neuron 96:17-42. https://doi.org/10.1016/j.neuron.2017.07.030

41. Ito H, Kanno I, Ibaraki M, Hatazawa J (2002) Effect of aging on cerebral vascular response to Paco2 changes in humans as measured by positron emission tomography. J Cereb Blood Flow Metab 22:997-1003. https://doi.org/10.1097/00004647200208000-00011

42. Jamadar SD (2020) The CRUNCH model does not account for load-dependent changes in visuospatial working memory in older adults. Neuropsychologia 142:107446. https://doi.org/10.1016/j. neuropsychologia.2020.107446

43. Jefferson AL, Cambronero FE, Liu D, Moore EE, Neal JE, Terry JG, Nair S, Pechman KR, Rane S, Davis LT, Gifford KA, Hohman TJ, Bell SP, Wang TJ, Beckman JA, Carr JJ (2018) Higher aortic stiffness is related to lower cerebral blood flow and preserved cerebrovascular reactivity in older adults. Circulation 138:1951-1962. https://doi.org/10.1161/CIRCULATIONAHA. 118.032410

44. Jørgensen LG, Perko M, Hanel B, Schroeder TV, Secher NH (1992) Middle cerebral artery flow velocity and blood flow during exercise and muscle ischemia in humans. J Appl Physiol (1985) 72:1123-1132. https://doi.org/10.1152/jappl.1992.72.3.1123

45. Kalaria RN (2018) The pathology and pathophysiology of vascular dementia. Neuropharmacology 134:226-239. https://doi.org/ 10.1016/j.neuropharm.2017.12.030

46. Kannurpatti SS, Motes MA, Rypma B, Biswal BB (2010) Neural and vascular variability and the fMRI-BOLD response in normal aging. Magn Reson Imaging 28:466-476. https://doi.org/10.1016/ j.mri.2009.12.007

47. Kastrup A, Dichgans J, Niemeier M, Schabet M (1998) Changes of cerebrovascular $\mathrm{CO}<\mathrm{sub}>2</$ sub $>$ reactivity during normal aging. Stroke 29:1311-1314. https://doi.org/10.1161/01.STR.29.7. 1311

48. Kim Y-S, Krogh-Madsen R, Rasmussen P, Plomgaard P, Ogoh S, Secher NH, van Lieshout JJ (2007) Effects of hyperglycemia on the cerebrovascular response to rhythmic handgrip exercise. Am J Physiol Heart Circ Physiol 293:H467-H473. https://doi.org/10. 1152/ajpheart.00045.2007

49. Kim HY, Seo K, Jeon HJ, Lee U, Lee H (2017) Application of functional near-infrared spectroscopy to the study of brain function in humans and animal models. Mol Cell 40:523-532. https:// doi.org/10.14348/molcells.2017.0153

50. Kisler K, Nelson AR, Montagne A, Zlokovic BV (2017) Cerebral blood flow regulation and neurovascular dysfunction in Alzheimer disease. Nat Rev Neurosci 18:419-434. https://doi. org/10.1038/nrn.2017.48

51. Kneser M, Kohlmann T, Pokorny J, Tost F (2009) Age related decline of microvascular regulation measured in healthy individuals by retinal dynamic vessel analysis. Med Sci Monit 15:Cr436Cr441

52. Kucharska-Newton AM, Stoner L, Meyer ML (2019) Determinants of vascular age: an epidemiological perspective. Clin Chem 65:108-118. https://doi.org/10.1373/clinchem.2018. 287623

53. Lassen NA (1985) Normal average value of cerebral blood flow in younger adults is $50 \mathrm{ml} / 100 \mathrm{~g} / \mathrm{min}$. J Cereb Blood Flow Metab 5: 347-349. https://doi.org/10.1038/jcbfm.1985.48

54. Lee YK, Rothwell PM, Payne SJ, Webb AJS (2020) Reliability, reproducibility and validity of dynamic cerebral autoregulation in a large cohort with transient ischaemic attack or minor stroke. Physiol Meas 41:095002. https://doi.org/10.1088/1361-6579/ abad49

55. Li Y, Choi WJ, Wei W, Song S, Zhang Q, Liu J, Wang RK (2018) Aging-associated changes in cerebral vasculature and blood flow as determined by quantitative optical coherence tomography angiography. Neurobiol Aging 70:148-159. https://doi.org/10.1016/ j.neurobiolaging.2018.06.017

56. Lindegaard KF, Lundar T, Wiberg J, Sjøberg D, Aaslid R, Nornes H (1987) Variations in middle cerebral artery blood flow investigated with noninvasive transcranial blood velocity measurements. Stroke 18:1025-1030. https://doi.org/10.1161/01.STR.18.6.1025

57. Lipecz A, Csipo T, Tarantini S, Hand RA, Ngo BN, Conley S, Nemeth G, Tsorbatzoglou A, Courtney DL, Yabluchanska V, Csiszar A, Ungvari ZI, Yabluchanskiy A (2019) Age-related impairment of neurovascular coupling responses: a dynamic vessel 
analysis (DVA)-based approach to measure decreased flicker light stimulus-induced retinal arteriolar dilation in healthy older adults. Geroscience 41:341-349. https://doi.org/10.1007/s11357-01900078-y

58. Lipsitz LA, Mukai S, Hamner J, Gagnon M, Babikian V (2000) Dynamic regulation of middle cerebral artery blood flow velocity in aging and hypertension. Stroke 31:1897-1903. https://doi.org/ 10.1161/01.str.31.8.1897

59. Liu X, Czosnyka M, Donnelly J, Budohoski KP, Varsos GV, Nasr N, Brady KM, Reinhard M, Hutchinson PJ, Smielewski P (2015) Comparison of frequency and time domain methods of assessment of cerebral autoregulation in traumatic brain injury. J Cereb Blood Flow Metab 35:248-256. https://doi.org/10.1038/jcbfm.2014.192

60. Lourenço CF, Ledo A, Caetano M, Barbosa RM, Laranjinha J (2018) Age-dependent impairment of neurovascular and neurometabolic coupling in the hippocampus. Front Physiol 9. https://doi.org/10.3389/fphys.2018.00913

61. Madureira J, Castro P, Azevedo E (2017) Demographic and systemic hemodynamic influences in mechanisms of cerebrovascular regulation in healthy adults. J Stroke Cerebrovasc Dis 26:500 508. https://doi.org/10.1016/j.jstrokecerebrovasdis.2016.12.003

62. Maggio P, Salinet AS, Robinson TG, Panerai RB (2014) Influence of $\mathrm{CO} 2$ on neurovascular coupling: interaction with dynamic cerebral autoregulation and cerebrovascular reactivity. Phys Rep 2: e00280. https://doi.org/10.1002/phy2.280

63. Mahajan A (2015) Selection bias: selection of controls as a critical issue in the interpretation of results in a case control study. Indian J Med Res 142:768. https://doi.org/10.4103/0971-5916.174574

64. Mahdi A, Nikolic D, Birch AA, Olufsen MS, Panerai RB, Simpson DM, Payne SJ (2017) Increased blood pressure variability upon standing up improves reproducibility of cerebral autoregulation indices. Med Eng Phys 47:151-158. https://doi.org/10. 1016/j.medengphy.2017.06.006

65. Mehagnoul-Schipper DJ, Vloet LCM, Colier WNJM, Hoefnagels WHL, Jansen RWMM (2000) Cerebral oxygenation declines in healthy elderly subjects in response to assuming the upright position. Stroke 31:1615-1620. https://doi.org/10.1161/01.STR.31.7. 1615

66. Mehagnoul-Schipper DJ, Colier WN, Jansen RW (2001) Reproducibility of orthostatic changes in cerebral oxygenation in healthy subjects aged 70 years or older. Clin Physiol 21:7784. https://doi.org/10.1046/j.1365-2281.2001.00290.x

67. Metea MR, Newman EA (2006) Glial cells dilate and constrict blood vessels: a mechanism of neurovascular coupling. J Neurosci 26:2862-2870. https://doi.org/10.1523/jneurosci.4048-05.2006

68. Minhas JS, Haunton VJ, Robinson TG, Panerai RB (2019) Determining differences between critical closing pressure and resistance-area product: responses of the healthy young and old to hypocapnia. Pflugers Arch - Eur J Physiol 471:1117-1126. https://doi.org/10.1007/s00424-019-02290-3

69. Minhas JS, Rook W, Panerai RB, Hoiland RL, Ainslie PN, Thompson JP, Mistri AK, Robinson TG (2020) Pathophysiological and clinical considerations in the perioperative care of patients with a previous ischaemic stroke: a multidisciplinary narrative review. Br J Anaesth 124:183-196. https://doi.org/ 10.1016/j.bja.2019.10.021

70. Morcom AM, Henson RNA (2018) Increased prefrontal activity with aging reflects nonspecific neural responses rather than compensation. J Neurosci 38:7303-7313. https://doi.org/10.1523/ jneurosci.1701-17.2018

71. Murman DL (2015) The Impact of Age on Cognition. Semin Hear 36:111-121. https://doi.org/10.1055/s-0035-1555115

72. Murrell CJ, Cotter JD, Thomas KN, Lucas SJ, Williams MJ, Ainslie PN (2013) Cerebral blood flow and cerebrovascular reactivity at rest and during sub-maximal exercise: effect of age and 12-week exercise training. Age (Dordr) 35:905-920. https://doi. org/10.1007/s11357-012-9414-x

73. Myrum C (2019) Is PASA Passe?: Rethinking compensatory mechanisms in cognitive aging. J Neurosci 39:786-787. https:// doi.org/10.1523/jneurosci.2348-18.2018

74. Narayanan K, Collins JJ, Hamner J, Mukai S, Lipsitz LA (2001) Predicting cerebral blood flow response to orthostatic stress from resting dynamics: effects of healthy aging. Am J Phys Regul Integr Comp Phys 281:R716-R722. https://doi.org/10.1152/ ajpregu.2001.281.3.R716

75. United Nations, Department of Economic and Social Affairs, Population Division (2020) World Population Ageing 2019 (ST/ ESA/SER. A/444)

76. Nowak-Flück D, Ainslie PN, Bain AR, Ahmed A, Wildfong KW, Morris LE, Phillips AA, Fisher JP (2018) Effect of healthy aging on cerebral blood flow, $\mathrm{CO} 2$ reactivity, and neurovascular coupling during exercise. J Appl Physiol 125:1917-1930. https://doi. org/10.1152/japplphysiol.00050.2018

77. Numan T, Bain AR, Hoiland RL, Smirl JD, Lewis NC, Ainslie PN (2014) Static autoregulation in humans: a review and reanalysis. Med Eng Phys 36:1487-1495. https://doi.org/10.1016/j. medengphy.2014.08.001

78. O'Brien JL, O'Keefe KM, LaViolette PS, DeLuca AN, Blacker D, Dickerson BC, Sperling RA (2010) Longitudinal fMRI in elderly reveals loss of hippocampal activation with clinical decline. Neurology 74:1969-1976. https://doi.org/10.1212/WNL. 0b013e3181e3966e

79. Ogoh S, Fisher JP, Young CN, Fadel PJ (2011) Impact of age on critical closing pressure of the cerebral circulation during dynamic exercise in humans. Exp Physiol 96:417-425. https://doi.org/10. 1113/expphysiol.2010.055871

80. Orlandi G, Murri L (1996) Transcranial Doppler assessment of cerebral flow velocity at rest and during voluntary movements in young and elderly healthy subjects. Int J Neurosci 84:45-53. https://doi.org/10.3109/00207459608987249

81. Ortega-Gutierrez S, Petersen N, Masurkar A, Reccius A, Huang A, Li M, Choi JH, Marshall RS (2014) Reliability, asymmetry, and age influence on dynamic cerebral autoregulation measured by spontaneous fluctuations of blood pressure and cerebral blood flow velocities in healthy individuals. J Neuroimaging 24:379 386. https://doi.org/10.1111/jon.12019

82. Oudegeest-Sander MH, van Beek AH, Abbink K, Olde Rikkert MG, Hopman MT, Claassen JA (2014) Assessment of dynamic cerebral autoregulation and cerebrovascular $\mathrm{CO} 2$ reactivity in ageing by measurements of cerebral blood flow and cortical oxygenation. Exp Physiol 99:586-598. https://doi.org/10.1113/ expphysiol.2013.076455

83. Panerai RB (2003) The critical closing pressure of the cerebral circulation. Med Eng Phys 25:621-632

84. Panerai RB (2008) Cerebral autoregulation: from models to clinical applications. Cardiovasc Eng 8:42-59. https://doi.org/10. 1007/s10558-007-9044-6

85. Panerai RB (2009) Transcranial Doppler for evaluation of cerebral autoregulation. Clin Auton Res 19:197-211. https://doi.org/10. 1007/s10286-009-0011-8

86. Panerai RB (2014) Nonstationarity of dynamic cerebral autoregulation. Med Eng Phys 36:576-584. https://doi.org/10.1016/j. medengphy.2013.09.004

87. Panerai RB, Kelsall AW, Rennie JM, Evans DH (1996) Analysis of cerebral blood flow autoregulation in neonates. IEEE Trans Biomed Eng 43:779-788. https://doi.org/10.1109/10.508541

88. Panerai RB, Moody M, Eames PJ, Potter JF (2005) Cerebral blood flow velocity during mental activation: interpretation with different models of the passive pressure-velocity relationship. J Appl Physiol (1985) 99:2352-2362. https://doi.org/10.1152/ japplphysiol.00631.2005 
89. Panerai RB, Saeed NP, Robinson TG (2015) Cerebrovascular effects of the thigh cuff maneuver. Am J Physiol Heart Circ Physiol 308:H688-H696. https://doi.org/10.1152/ajpheart.00887.2014

90. Panerai RB, Barnes SC, Nath M, Ball N, Robinson TG, Haunton VJ (2018) Directional sensitivity of dynamic cerebral autoregulation in squat-stand maneuvers. Am J Phys Regul Integr Comp Phys 315:R730-R740. https://doi.org/10.1152/ajpregu.00010. 2018

91. Patel N, Panerai RB, Haunton V, Katsogridakis E, Saeed NP, Salinet A, Brodie F, Syed N, D'Sa S, Robinson TG (2016) The Leicester cerebral haemodynamics database: normative values and the influence of age and sex. Physiol Meas 37:1485-1498. https://doi.org/10.1088/0967-3334/37/9/1485

92. Paulson OB, Strandgaard S, Edvinsson L (1990) Cerebral autoregulation. Cerebrovasc Brain Metab Rev 2:161-192

93. Peebles KC, Richards AM, Celi L, McGrattan K, Murrell CJ, Ainslie PN (2008) Human cerebral arteriovenous vasoactive exchange during alterations in arterial blood gases. J Appl Physiol 105:1060-1068. https://doi.org/10.1152/japplphysiol.90613.2008

94. Persson J, Nyberg L, Lind J, Larsson A, Nilsson LG, Ingvar M, Buckner RL (2006) Structure-function correlates of cognitive decline in aging. Cereb Cortex 16:907-915. https://doi.org/10.1093/ cercor/bhj036

95. Petersen RC (2016) Mild cognitive impairment. Continuum (Minneap Minn) 22:404-418. https://doi.org/10.1212/con. 0000000000000313

96. Petersen SE, Dubis JW (2012) The mixed block/event-related design. Neuroimage 62:1177-1184. https://doi.org/10.1016/j. neuroimage.2011.09.084

97. Phillips AA, Chan FH, Zheng MM, Krassioukov AV, Ainslie PN (2016) Neurovascular coupling in humans: physiology, methodological advances and clinical implications. J Cereb Blood Flow Metab 36:647-664. https://doi.org/10.1177/0271678x15617954

98. Alzheimer's Disease International (2015) World Alzheimer Report 2015: The global impact of dementia. Alzheimer's Disease International, London, pp 1-87. Available from: https:// www.alzint.org/resource/world-alzheimer-report-2015/

99. Rasmussen P, Plomgaard P, Krogh-Madsen R, Kim Y-S, van Lieshout JJ, Secher NH, Quistorff B (2006) MCA Vmean and the arterial lactate-to-pyruvate ratio correlate during rhythmic handgrip. J Appl Physiol (1985) 101:1406-1411. https://doi.org/ 10.1152/japplphysiol.00423.2006

100. Reinhard M, Gerds TA, Grabiak D, Zimmermann PR, Roth M, Guschlbauer B, Timmer J, Czosnyka M, Weiller C, Hetzel A (2008) Cerebral dysautoregulation and the risk of ischemic events in occlusive carotid artery disease. J Neurol 255:1182-1189. https://doi.org/10.1007/s00415-008-0865-z

101. Reuter-Lorenz PA, Cappell KA (2008) Neurocognitive aging and the compensation hypothesis. Curr Dir Psychol Sci 17:177-182. https://doi.org/10.1111/j.1467-8721.2008.00570.x

102. Robertson AD, Edgell H, Hughson RL (2014) Assessing cerebrovascular autoregulation from critical closing pressure and resistance area product during upright posture in aging and hypertension. Am J Phys Heart Circ Phys 307:H124-H133. https://doi.org/ 10.1152/ajpheart.00086.2014

103. Ruitenberg A, den Heijer T, Bakker SLM, van Swieten JC, Koudstaal PJ, Hofman A, Breteler MMB (2005) Cerebral hypoperfusion and clinical onset of dementia: the Rotterdam Study. Ann Neurol 57:789-794. https://doi.org/10.1002/ana.20493

104. Sanders ML, Claassen J, Aries M, Bor-Seng-Shu E, Caicedo A, Chacon M, Gommer ED, Van Huffel S, Jara JL, Kostoglou K, Mahdi A, Marmarelis VZ, Mitsis GD, Muller M, Nikolic D, Nogueira RC, Payne SJ, Puppo C, Shin DC, Simpson DM, Tarumi T, Yelicich B, Zhang R, Panerai RB, Elting JWJ (2018) Reproducibility of dynamic cerebral autoregulation parameters: a multi-centre, multi-method study. Physiol Meas 39:125002. https://doi.org/10.1088/1361-6579/aae9fd

105. Sanders ML, Elting JWJ, Panerai RB, Aries M, Bor-Seng-Shu E, Caicedo A, Chacon M, Gommer ED, Van Huffel S, Jara JL, Kostoglou K, Mahdi A, Marmarelis VZ, Mitsis GD, Müller M, Nikolic D, Nogueira RC, Payne SJ, Puppo C, Shin DC, Simpson DM, Tarumi T, Yelicich B, Zhang R, Claassen JAHR (2019) Dynamic cerebral autoregulation reproducibility is affected by physiological variability. Front Physiol 10. https://oi.org/10. 3389/fphys.2019.00865

106. Schneider-Garces NJ, Gordon BA, Brumback-Peltz CR, Shin E, Lee Y, Sutton BP, Maclin EL, Gratton G, Fabiani M (2010) Span, $\mathrm{CRUNCH}$, and beyond: working memory capacity and the aging brain. J Cogn Neurosci 22:655-669. https://doi.org/10.1162/jocn. 2009.21230

107. Scuteri A, Morrell CH, Orrù M, Strait JB, Tarasov KV, Ferreli LA, Loi F, Pilia MG, Delitala A, Spurgeon H, Najjar SS, AlGhatrif M, Lakatta EG (2014) Longitudinal perspective on the conundrum of central arterial stiffness, blood pressure, and aging. Hypertension 64:1219-1227. https://doi.org/10.1161/hypertensionaha.114. 04127

108. Seals DR, Kaplon RE, Gioscia-Ryan RA, LaRocca TJ (2014) You're only as old as your arteries: translational strategies for preserving vascular endothelial function with aging. Physiology (Bethesda) 29:250-264. https://doi.org/10.1152/physiol.00059. 2013

109. Singh S, Bajorek B (2014) Defining 'elderly' in clinical practice guidelines for pharmacotherapy. Pharm Pract (Granada) 12:489. https://doi.org/10.4321/s1886-36552014000400007

110. Smielewski P, Czosnyka M, Kirkpatrick P, McEroy H, Rutkowska H, Pickard JD (1996) Assessment of cerebral autoregulation using carotid artery compression. Stroke 27:21972203. https://doi.org/10.1161/01.str.27.12.2197

111. Sorond FA, Khavari R, Serrador JM, Lipsitz LA (2005) Regional cerebral autoregulation during orthostatic stress: age-related differences. J Gerontol A Biol Sci Med Sci 60:1484-1487. https:// doi.org/10.1093/gerona/60.11.1484

112. Sorond FA, Schnyer DM, Serrador JM, Milberg WP, Lipsitz LA (2008) Cerebral blood flow regulation during cognitive tasks: effects of healthy aging. Cortex 44:179-184. https://doi.org/10. 1016/j.cortex.2006.01.003

113. Spronck B, Martens EGHJ, Gommer ED, van de Vosse FN (2012) A lumped parameter model of cerebral blood flow control combining cerebral autoregulation and neurovascular coupling. Am J Phys Heart Circ Phys 303:H1143-H1153. https://doi.org/10. 1152/ajpheart.00303.2012

114. Stefanidis KB, Askew CD, Klein T, Lagopoulos J, Summers MJ (2019) Healthy aging affects cerebrovascular reactivity and pressure-flow responses, but not neurovascular coupling: a cross-sectional study. PLoS One 14:e0217082. https://doi.org/10. 1371/journal.pone. 0217082

115. Stroobant N, Vingerhoets G (2000) Transcranial Doppler ultrasonography monitoring of cerebral hemodynamics during performance of cognitive tasks: a review. Neuropsychol Rev 10:213231

116. Tameem A, Krovvidi H (2013) Cerebral physiology. Contin Educ Anaesth Crit Care Pain 13:113-118. https://doi.org/10.1093/ bjaceaccp/mkt001

117. Tarantini S, Tran CHT, Gordon GR, Ungvari Z, Csiszar A (2017) Impaired neurovascular coupling in aging and Alzheimer's disease: contribution of astrocyte dysfunction and endothelial impairment to cognitive decline. Exp Gerontol 94:52-58. https://doi.org/ 10.1016/j.exger.2016.11.004

118. Tarumi T, Zhang R (2018) Cerebral blood flow in normal aging adults: cardiovascular determinants, clinical implications, and 
aerobic fitness. J Neurochem 144:595-608. https://doi.org/10. 1111/jnc. 14234

119. Teixeira SC, Madureira JB, Azevedo EI, Castro PM (2019) Ageing affects the balance between central and peripheral mechanisms of cerebrovascular regulation with increasing influence of systolic blood pressure levels. Eur J Appl Physiol 119:519-529. https://doi.org/10.1007/s00421-018-4036-3

120. Thomas BP, Yezhuvath US, Tseng BY, Liu P, Levine BD, Zhang $\mathrm{R}, \mathrm{Lu} \mathrm{H}$ (2013) Life-long aerobic exercise preserved baseline cerebral blood flow but reduced vascular reactivity to $\mathrm{CO} 2$. J Magn Reson Imaging 38:1177-1183. https://doi.org/10.1002/jmri. 24090

121. Tiecks FP, Lam AM, Aaslid R, Newell DW (1995) Comparison of static and dynamic cerebral autoregulation measurements. Stroke 26:1014-1019. https://doi.org/10.1161/01.STR.26.6.1014

122. Tomoto T, Riley J, Turner M, Zhang R, Tarumi T (2020) Cerebral vasomotor reactivity during hypo- and hypercapnia across the adult lifespan. J Cereb Blood Flow Metab 40:600-610. https:// doi.org/10.1177/0271678x19828327

123. World Health Organisation (2006) The global burden of cerebrovascular disease. World Health Organisation, Geneva Available from: https://www.who.int/healthinfo/statistics/bod cerebrovasculardiseasestroke.pdf

124. Tzeng YC, Ainslie PN (2014) Blood pressure regulation IX: cerebral autoregulation under blood pressure challenges. Eur J Appl Physiol 114:545-559. https://doi.org/10.1007/s00421-013-2667-y

125. Tzeng YC, Panerai RB (2018) CrossTalk proposal: dynamic cerebral autoregulation should be quantified using spontaneous blood pressure fluctuations. J Physiol 596:3-5. https://doi.org/ 10.1113/jp273899

126. Tzeng YC, Ainslie PN, Cooke WH, Peebles KC, Willie CK, MacRae BA, Smirl JD, Horsman HM, Rickards CA (2012) Assessment of cerebral autoregulation: the quandary of quantification. Am J Physiol Heart Circ Physiol 303:H658-H671. https:// doi.org/10.1152/ajpheart.00328.2012

127. van Beek AH, Claassen JA, Rikkert MG, Jansen RW (2008) Cerebral autoregulation: an overview of current concepts and methodology with special focus on the elderly. J Cereb Blood Flow Metab 28: 1071-1085. https://doi.org/10.1038/jcbfm.2008.13

128. van Beek AHEA, Olde Rikkert MGM, Pasman JW, Hopman MTE, Claassen JAHR (2010) Dynamic cerebral autoregulation in the old using a repeated sit-stand maneuver. Ultrasound Med Biol 36:192201. https://doi.org/10.1016/j.ultrasmedbio.2009.10.011

129. Vermeij A, Meel-van den Abeelen ASS, Kessels RPC, van Beek AHEA, Claassen JAHR (2014) Very-low-frequency oscillations of cerebral hemodynamics and blood pressure are affected by aging and cognitive load. NeuroImage 85:608-615. https://oi. org/10.1016/j.neuroimage.2013.04.107
130. Wang F, Cao Y, Ma L, Pei H, Rausch WD, Li H (2018) Dysfunction of cerebrovascular endothelial cells: prelude to vascular dementia. Front Aging Neurosci 10:376. https://doi.org/10. 3389/fnagi.2018.00376

131. Wentland AL, Grist TM, Wieben O (2014) Review of MRI-based measurements of pulse wave velocity: a biomarker of arterial stiffness. Cardiovasc Diagn Ther 4:193-206. https://doi.org/10.3978/ j.issn.2223-3652.2014.03.04

132. West KL, Zuppichini MD, Turner MP, Sivakolundu DK, Zhao Y, Abdelkarim D, Spence JS, Rypma B (2019) BOLD hemodynamic response function changes significantly with healthy aging. NeuroImage 188:198-207. https://doi.org/10.1016/j.neuroimage. 2018.12.012

133. Willie CK, Tzeng YC, Fisher JA, Ainslie PN (2014) Integrative regulation of human brain blood flow. J Physiol 592:841-859. https://doi.org/10.1113/jphysiol.2013.268953

134. Woodard JL, Seidenberg M, Nielson KA, Smith JC, Antuono P, Durgerian S, Guidotti L, Zhang Q, Butts A, Hantke N, Lancaster M, Rao SM (2010) Prediction of cognitive decline in healthy older adults using fMRI. J Alzheimers Dis 21:871-885. https://doi.org/ 10.3233/jad-2010-091693

135. Xing CY, Tarumi T, Meijers RL, Turner M, Repshas J, Xiong L, Ding K, Vongpatanasin W, Yuan LJ, Zhang R (2017) Arterial pressure, heart rate, and cerebral hemodynamics across the adult life span. Hypertension 69:712-720. https://doi.org/10.1161/ hypertensionaha.116.08986

136. Yamaguchi F, Meyer JS, Sakai F, Yamamoto M (1979) Normal human aging and cerebral vasoconstrictive responses to hypocapnia. J Neurol Sci 44:87-94. https://doi.org/10.1016/ 0022-510X(79)90226-0

137. Yang T, Sun Y, Lu Z, Leak RK, Zhang F (2017) The impact of cerebrovascular aging on vascular cognitive impairment and dementia. Ageing Res Rev 34:15-29. https://doi.org/10.1016/j.arr. 2016.09.007

138. Zaletel M, Strucl M, Pretnar-Oblak J, Zvan B (2005) Age-related changes in the relationship between visual evoked potentials and visually evoked cerebral blood flow velocity response. Funct Neurol 20:115-120

139. Zhu YS, Tarumi T, Tseng BY, Palmer DM, Levine BD, Zhang R (2013) Cerebral vasomotor reactivity during hypo- and hypercapnia in sedentary elderly and Masters athletes. J Cereb Blood Flow Metab 33:1190-1196. https://doi.org/10.1038/jcbfm.2013.66

Publisher's note Springer Nature remains neutral with regard to jurisdictional claims in published maps and institutional affiliations. 